\title{
Capillary flow in UHPFRC with synthetic fibers, under high tensile stresses
}

\author{
Amir Hajiesmaeili *, Emmanuel Denarié \\ Maintenance and Safety of Structures, Ecole Polytechnique Fédérale de Lausanne, Station 18, GC A3 398, CH-1015 Lausanne, Switzerland
}

\section{A R T I C L E I N F O}

\section{Keywords:}

Capillary absorption

UHPFRC

PE-UHPFRC

UHMW-PE fibers

Tensile response

Crack characteristics

\begin{abstract}
A B S T R A C T
A novel Ultra High-Performance Fiber Reinforced Concrete (UHPFRC) mix with synthetic fibers and a low clinker matrix, henceforth referred to as $P E-U H P F R C$, has been developed for structural applications. It exhibits a high tensile elastic limit above $7 \mathrm{MPa}$, a tensile strength of more than $10 \mathrm{MPa}$, and a very high tensile hardening domain of above $3.5 \%$. In order to effectively use this material, its protective properties have been investigated on the basis of the effect of tensile deformation and subsequent cracking on water transport properties, for a wide range of tensile strain. A special setup was developed to measure the capillary absorption of liquids while the specimen is under tension. The results show a considerable reduction in capillary absorption in case of PEUHPFRC compared with Strain Hardening Cement-based Composites (SHCC). Moreover, the results highlight the considerable effect of the onset of cracking on capillary absorption.
\end{abstract}

\section{Introduction}

The ever-increasing demand of society for the build environments on one hand and the limited material resources, on the other hand, have promoted the implementation of high and ultra-high-performance materials towards sustainability during the last few decades. Meanwhile, UHPFRC has successfully gained the ground and has proved its potential to be one of the solutions to contain the explosion of the costs (economy and environment) along with its numerous applications [1-3]. Continuing this trend, PE-UHPFRC is developed with $75 \%$ reduced environmental impact compared to conventional UHPFRC mixes by replacing the steel fibers with Ultra High Molecular Weight Polyethylene (UHMW-PE) ones and replacing $50 \%$ of the clinker with limestone fillers [4]. The high tensile elastic limit above $7 \mathrm{MPa}$, tensile strength of more than $10 \mathrm{MPa}$, and tensile deformation capacity of more than 3.5\% make the newly developed UHPFRC well adapted for structural applications. In order to effectively use this material, its protective properties need to be investigated on the basis of the effect of tensile deformation and subsequent cracking on water transport properties and accordingly on the durability of the material.

Deterioration mechanisms in cementitious materials are principally caused by insufficient protection followed by ingress of catalysts like water and aggressive agents in the material. Sorptivity and permeability are used as a measure for liquid transport properties and thereupon for the durability of cementitious materials. Permeability relates the movement of moisture through a saturated porous medium under a pressure gradient. Consequently, it is not entirely representative as structures made from cementitious materials are rarely saturated and exposed to strong pressure gradients in the building environment (excluding underground and offshore structures). Hence, sorptivity is a more realistic property to describe the liquid transport and durability of cementitious materials in structural applications were capillary flow prevails. There are two general approaches to model and analysis the sorptivity of cementitious materials in literature, which both yield a linear relationship between capillary absorption and the square root of time. The first approach is based on an extension of Darcy's law to unsaturated porous media [5] and the second approach is based on the Lucas-Washburn equation [6,7], which describes the dynamic flow equation of liquids in a capillary tube. The latter approach is more employed to describe the capillary absorption of cracked cementitious materials [8-10] in which the sorptivity corresponds to the square root of crack width. Furthermore, Zaccardi et al. [11] reported a better correlation between the water capillary absorption, and the fourth root of time for normal concretes with ordinary Portland cement and pozzolanic Portland cement.

Different measurements for evaluating the transport properties, such as capillary absorption, gas penetration, and liquid penetration were carried out on undamaged UHPFRC specimens [12-18], which all show a considerable improvement compared to ordinary and high strength concretes. Roux et al. [18] showed that the capillary absorption of UHPFRC is over ten times less than that of conventional concretes. Furthermore, they reported that the air permeability and chloride

\footnotetext{
* Corresponding author.

E-mail addresses: Amir.Hajiesmaeili@epfl.ch (A. Hajiesmaeili), Emmanuel.Denarie@epfl.ch (E. Denarié).
} 
diffusion coefficient of UHPFRC are at least two orders of magnitude less than that of C30 and C80 concretes. Tam et al. [16] found that the water permeability coefficient of UHPFRC is lower than that of normal concrete by one or two orders of magnitude. The resistance of UHPFRC to the penetration of chloride ions was investigated by many researchers $[3,14,18]$ and it was shown that UHPFRC has a much higher resistance to penetration of chloride ions than ordinary concretes and that the depth affected from the surface of exposed areas is remarkably lower in UHPFRC. Furthermore, numerous studies have confirmed the durability of structures built with UHPFRC after several years of exposure to severe conditions [19-23]. These features are attributed to the homogenous and highly dense microstructure of UHPFRC.

At service state, structural elements experience different levels of mechanical loading under both autogenous (eigenstresses) and exogenous actions (climate conditions, live loads, deadweight, accidental actions, fire, etc.), well documented in the literature [24-26]. However, only a few notable studies were carried out on the effects of damage on the transport properties of UHPFRC [24-30]. Wang et al. [26] studied the influence of imposed compressive stresses on capillary absorption of UHPFRC and found that the absorbed water mass increased by a factor of two when the specimens were loaded up to $50 \%$ of their compressive strength. The effect of tensile stresses on capillary absorption was investigated by Wittmann et al. [24] and it was shown that the capillary absorption is significantly increased if the material is subjected to tensile stresses higher than $50 \%$ of its tensile strength. Accordingly, Wang et al. [25] reported that the sorptivity of UHPFRC increases by $30 \%, 45 \%$, $77 \%$ and $95 \%$ for load levels of $50 \%, 60 \%, 70 \%$ and $80 \%$ of its splitting tensile strength, respectively.

ECC (Engineered Cementitious Composite) [31], SHCC [32] and HSHDC (High Strength, High-Ductility Concrete) [33] are classes of synthetic fiber-reinforced cementitious composites with high tensile deformation capacity. Although from a mechanical properties point of view, HSHDC is the closest to PE-UHPFRC, to the best of authors' knowledge, no extensive research has been reported in the open literature on transport properties of this material. However, the durability of ECC and SHCC, which are designed to limit the ingress of potentially deleterious substances by controlling cracks width, were investigated in terms of transport properties, as a function of different crack width and strain levels by several researchers [34-43]. The results show that the water permeability under pressure is very much linked to the crack features and cracking patterns. Regardless of the material type (SHCC, normal concrete and UHPFRC), the permeability to liquids under pressure starts increasing at a much faster rate with increasing crack width after 0.05 to $0.1 \mathrm{~mm}[30,40,41]$. However, the capillary water absorption in SHCC specimens was found to increase drastically by increasing the strain in the specimens even before a crack opening of $0.1 \mathrm{~mm}$ [39]. Investigations by means of neutron radiography showed that preexisting microcracks subjected to capillary absorption become waterfilled only after a few minutes [44]. Furthermore, increasing strains from 0 to $0.5 \%$ results in almost a $72 \%$ higher water capillary absorption [42]. Although the crack width plays an important role on the capillary absorption of cementitious materials, its effects have been underestimated in the aforementioned studies as the capillary absorption was determined after unloading the specimens.

In this study, an original test setup was developed in order to measure the capillary absorption of materials under tensile loading. The water sorptivity of tensile specimens made from PE-UHPFRC was investigated over a wide range of tensile deformation with the help of the developed setup. Afterwards, the specimens were unloaded and the capillary absorption of the same specimens was determined in accordance with EN13057:2002 standard [45], in order to compare the sorptivity under load and after unloading. As the cracking behavior highly affects the capillary absorption, Digital Image Correlation (DIC) was used to analyze the crack characteristics including crack pattern and width and investigate their effect on sorptivity. Finally, the results were put into perspective with existing experimental data on related
Table 1

Mix proportions of PE-UHPFRC (mix PE21).

\begin{tabular}{ll}
\hline Components & $\left(\mathrm{kg} / \mathrm{m}^{3}\right)$ \\
\hline Cement & 508 \\
Silica fume & 118 \\
Betocarb®-HP SL & 170 \\
Betoflow®-D & 389 \\
Quartz powder & 223 \\
Fine sand & 525 \\
Water & 165 \\
HRWRA & 27 \\
Ca(NO $)_{2}$ & 11 \\
UHMW PE fibers (Dyneema® SK99) & 19.6 \\
\hline
\end{tabular}

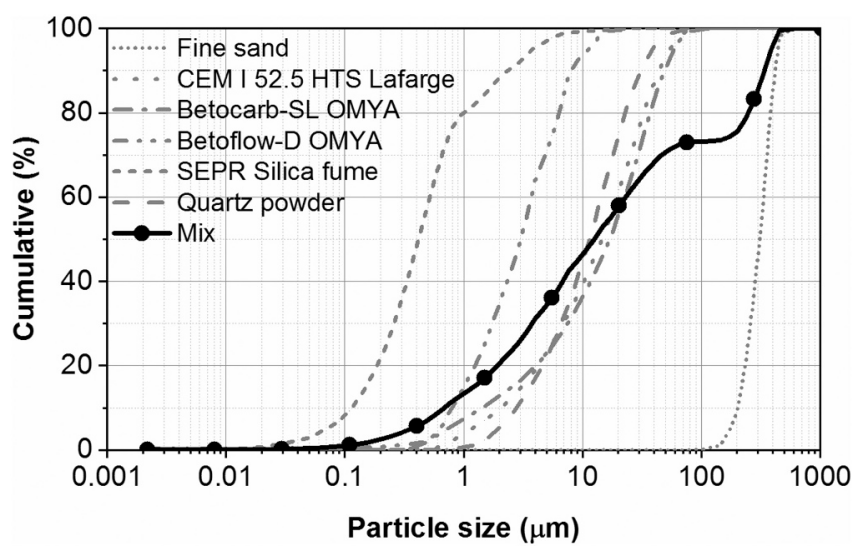

Fig. 1. PSD of the components and final mix.

materials.

\section{Material design}

A newly developed UHPFRC mix, named "PE-UHPFRC" (ref. mix PE21), was used for the present study. The Embodied Energy (EE) of this mix is reduced by $75 \%$ with respect to that of current UHPFRC mixes for structural applications, with steel fibers. In PE-UHPFRC mixes, the steel fibers are fully replaced by UHMW-PE ones and 50\% volume of the clinker is replaced by limestone fillers. Considering that the optimization of packing density and low w/fines ratio are the keys for obtaining Ultra high-performance cementitious composites, a generalization of the Compaction-Interaction Packing Model (CIPM) model [46] was derived and applied to optimize the mixture design [4]. Six different powders including cement CEM I 52.5 HTS Lafarge, two types of limestone filler of different gradings: Betoflow $\mathrm{D} \circledast$ and Betocarb SL ${ }^{\circledR}$ (OMYA), white silica fume from SEPR (BET $=14 \mathrm{~m}^{2} / \mathrm{g}$ ), quartz powder and fine quartz sand $\left(d_{50}=0.250 \mathrm{~mm}\right)$ were used in the mixes. Moreover, a modified Polycarboxylates-based HRWRA was used to maintain flowability and rheology of the mixture at the very low $w /$ fines ratio of 0.146 . The composition of the PE-UHPFRC mix is given in Table 1. Moreover, Fig. 1 shows the particle size distribution (PSD) of the powders used and of the mix. The packing density of the final mix was 0.81 based on the generalized CIPM, by using a compaction index of 9 for the calculations.

Table 2

Geometry and mechanical properties of PE Fiber.

\begin{tabular}{lc}
\hline Fiber properties & Values \\
\hline Diameter $\mathrm{d}_{\mathrm{f}}(\mu \mathrm{m})$ & 12 \\
Length $\mathrm{l}_{\mathrm{f}}(\mathrm{mm})$ & 6 \\
Nominal strength $(\mathrm{MPa})$ & 4100 \\
Nominal Young's modulus $(\mathrm{GPa})$ & 155 \\
Elongation at break $(\%)$ & 3.5 \\
Specific weight $\left(\mathrm{kg} / \mathrm{m}^{3}\right)$ & 980 \\
\hline
\end{tabular}



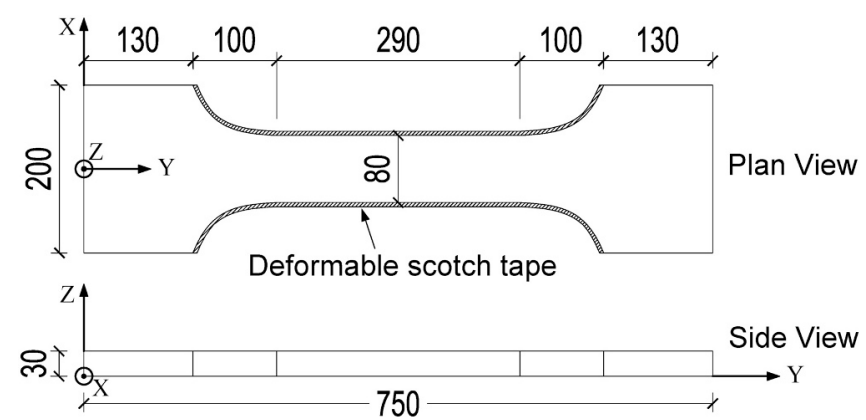

Fig. 2. Dumbbell specimen geometry (dimensions in $\mathrm{mm}$ ).

$\mathrm{Ca}\left(\mathrm{NO}_{3}\right)_{2}$ was employed in the form of a water-soluble compound in order to optimize the performance of the superplasticizer and reduce its dosage and thus the air content. At fresh state, the air content and the specific weight of the material were $4.5 \%$ and $2215 \mathrm{~kg} / \mathrm{m}^{3}$, respectively. Furthermore, the flow was $48 \%$ after ASTM C1437 [47], with a final diameter after 25 blows of $150 \mathrm{~mm}$.

The fibrous mix consisted of $2 \%$ vol. $6 \mathrm{~mm}$ long, chopped UHMW-PE fiber type SK 99 from DSM Dyneema ${ }^{\circledR}$. The mechanical properties and the geometry of these PE fibers are given in Table 2.

\section{Experimental procedure}

\subsection{Specimen design and preparation}

An original dumbbell specimen was designed with a thickness of 30 $\mathrm{mm}$ representative of that found in numerous applications of UHPFRC, either cast-on-site for rehabilitation or in structural uses with thin precast ribbed members. The specimen had $290 \mathrm{~mm}$ length with a constant cross-section, with a width of $80 \mathrm{~mm}$, on which three capillary chambers were installed (Figs. 2 and 5). The total length of the specimen was 750 $\mathrm{mm}$. In order to limit as far as possible stress concentrations, Neuber's model [48] was applied to determine the geometry of the $100 \mathrm{~mm}$ long transition zone between the specimen's ends and its central part. Fig. 2 shows the corresponding specimen geometry.

The specimens were cast horizontally in the molds from one end to

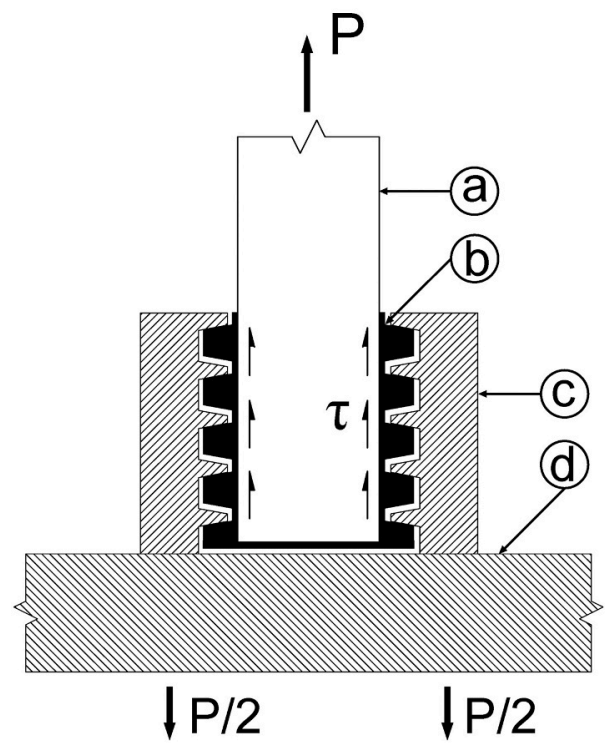

(A) the other, in a systematically repetitive procedure to obtain reproducible fiber orientation and distribution. The lower internal face of the molds was covered with a Controlled Permeability Formliner (CPF) - Zemdrain ${ }^{\circledR}$ sheet to avoid the water repellent effect of demolding oil. In order to avoid surfacing, the top surface of the specimen was covered immediately after pouring with a Zemdrain ${ }^{\circledR}$ sheet attached to a wood panel to guarantee a flat and uniform upper surface without air voids, after setting. Regarding the use of Zemdrain ${ }^{\circledR}$ sheets on the UHPFRC surfaces, it should be noted that according to [49], using these sheets had a negligible effect on the air permeability of concretes with a w/c ratio of 0.43 . It can thus be assumed that their effect on the mechanical and transport properties of the UHPFRC skin are negligible. Moreover, the lateral internal faces of the molds along the shoulders were covered with $1 \mathrm{~mm}$ thick deformable tape to prevent eigenstresses and restrained shrinkage cracks at an early age. The specimens were kept sealed after casting for 2 days at room temperature of $20 \pm 5{ }^{\circ} \mathrm{C}$. Thereupon demolding, the specimens were stored at room temperature of $20 \pm 5{ }^{\circ} \mathrm{C}$ under $95 \% \mathrm{RH}$. Before testing at 28 days, the specimens were washed with soap, to ensure removing of any fat with a water repellent effect. This was followed by a drying process at $50{ }^{\circ} \mathrm{C}$ up to a constant weight. Eventually, the specimens were stored in the laboratory at ambient conditions $\left(20^{\circ} \mathrm{C}\right.$ under $\left.50 \% \mathrm{RH}\right)$ for at least $12 \mathrm{~h}$.

\subsection{Tensile test}

In order to avoid as far as possible bending effects during the test, an optimized set-up was used with: (1) a stiff (4 columns) testing machine, (2) fixed/fixed support conditions for the specimen, and (3) a highly accurate alignment of the specimen thanks to a special procedure to link it directly to the machine without clamping. The dumbbell specimens were attached to the testing set-up by means of the "gluing without bonding" approach proposed by [50], and applied to dumbbell specimen by [51], Fig. 3. A steel shoe formed of plates with indented internal faces (c) on Fig. 3, was used as a form to cast resin indentations glued to the specimen, that helped transmit loads from the machine to the specimen by interlocking. In order to avoid adherence between the specimen and the indented metallic shoe, a demolding spray was applied on the internal indented faces of the later, before inserting the specimen coated with resin on its end in the shoe. This system guaranteed a uniform stress

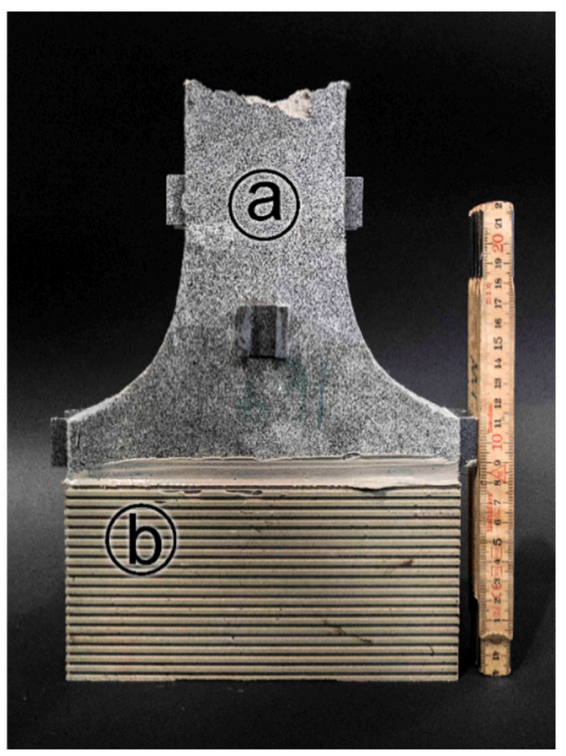

(B)

Fig. 3. (A) Schematic sketch of the fixture set-up of the uniaxial tensile test (adapted after [50]) and (B) Tensile specimen after testing, with (a) specimen, (b) hardened resin indentations glued to the specimen surface, (c) indented steel plate, and (d) base plate. 


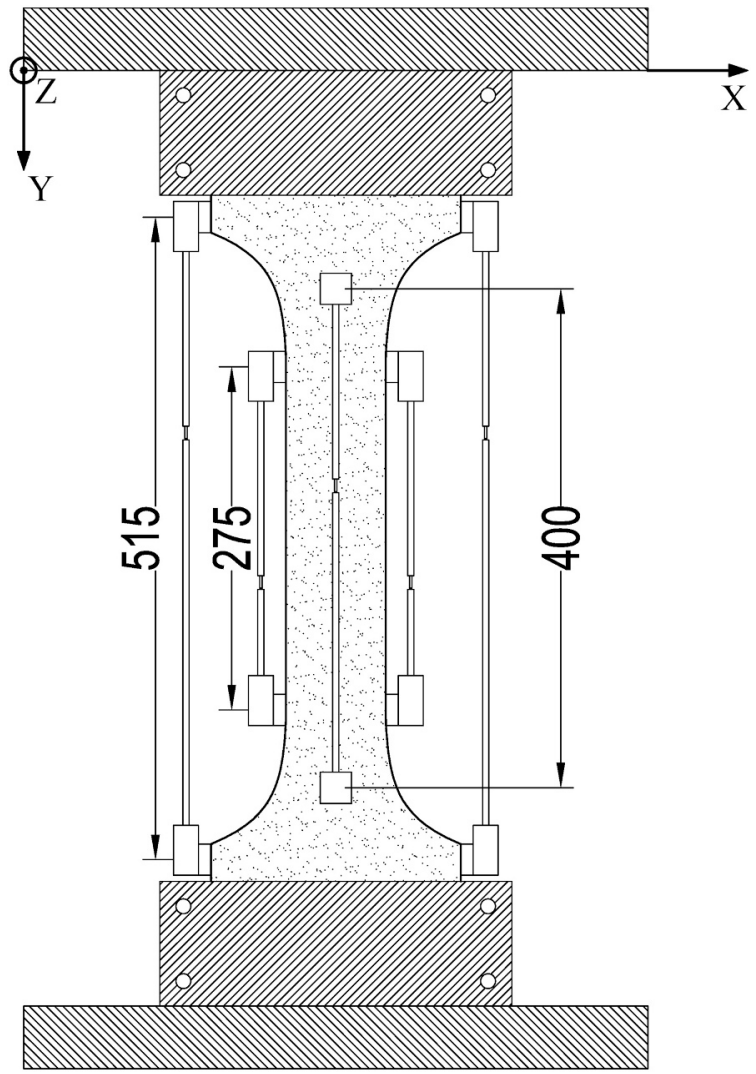

Fig. 4. Test setup and instrumentation of the tensile specimen (dimensions in $\mathrm{mm}$ ).

transfer without lateral restraint of the specimen. The top and bottom indented steel shoes were tightly bolted to stiff steel plates, (d) on Fig. 3, bolted directly on the machine's heads without any hinge.

The uniaxial tensile tests were conducted with a universal AMSLER testing machine (capacity: $1000 \mathrm{kN}$ ). The test was controlled by the mean value of two LVDT fixed on the specimen with a gauge length of $515 \mathrm{~mm}$, as shown in Fig. 4, with a closed-loop deformation rate of $0.003 \mathrm{~mm} / \mathrm{s}$. Two additional pairs of LVDT, set in two perpendicular planes, were used to determine the elongation of the specimen and check eccentricities under loading. The gauge lengths of the LVDT were $400 \mathrm{~mm}$ and $275 \mathrm{~mm}$ in XY and YZ planes, respectively.

\subsection{Crack measurement system}

A 3D Digital Image Correlation (DIC) system, was used in order to measure the surface deformations. The system consisted of two $29 \mathrm{MP}$ SVCam-hr29050 cameras with Zeiss Distagon35 lenses, connected to a PC. The digital images were analyzed by the Vic-3D 8 software in order to determine the surface deformation. In order to make an identifiable pattern, first the cast upper surface of the specimen was painted in white and then black aerosol paint spray was used to create the speckle pattern. The measurement area was $350 \mathrm{~mm} \times 80 \mathrm{~mm}$. The resolution of deformation measurement was $0.2 \mu \mathrm{m}$.

\subsection{Capillary absorption test}

An original setup was developed in order to measure capillary absorption while the specimen was loaded. The setup consisted of $3 \mathrm{cy}-$ lindrical chambers with an internal diameter of $60 \mathrm{~mm}$, which maintained the liquid in contact with the specimen surface. The chambers were made from Plexiglas that rested on an aluminum support. Two chambers (one for the specimen and the other one for the reference)

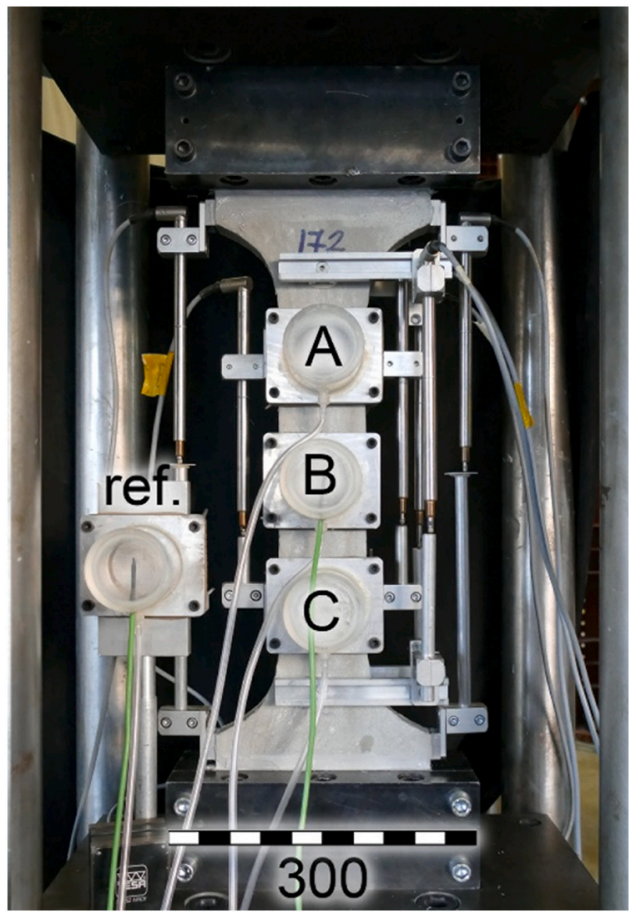

Fig. 5. Capillary absorption measurement setup with chambers A, B and C installed on the tensile specimen, and additional reference chamber for compensation of effect of temperature variations.

were equipped with thermocouples in order to have a live measurement of the liquid temperature during the test.

For the capillary measurements, three chambers were clamped on the constant cross-section of the specimens with the help of 4 threaded rods. A rubber gasket was placed between the specimen surface and the chamber's support in order to ensure the water tightness. Each chamber was then connected to a graduated glass pipette with a flexible plastic tube. A drop of oil was put over the water in the pipette to avoid evaporation and the liquid level in the pipettes corresponded to the level of the chambers to avoid hydrostatic pressure at the beginning of the test. The subsequent changes of the liquid level were then recorded using a non-contact optical measurement system based on a digital camera and real-time image processing. As a reference, one chamber was clamped on an aluminum plate and was placed close to the specimen in order to record the variation of the water level due to the effect of ambient condition such as temperature variations and evaporation. This variation was then subtracted from the water level of the other three chambers in order to have only the effect of capillary absorption. The installation of the capillary absorption setup is presented in Fig. 5.

After the capillary absorption test under tension was completed, the damaged dumbbell specimens were unloaded, and cores were extracted for the capillary absorption tests based on EN13057:2002 standard [45]. Three cylinders were cut throughout the full depth $(30 \mathrm{~mm})$ of the tensile specimen with water jet, at the exact locations which were in contact with the chambers during the capillary absorption measurement under tension, to be able to compare the results, Fig. 6 (a). Afterwards, the cylinders were oven dried until constant weight, at $50^{\circ} \mathrm{C}$. In order to ensure one-dimensional liquid transport, the side faces of the cylinders were sealed with paraffin and thereafter, the specimen was kept in the laboratory ambient conditions $\left(20^{\circ} \mathrm{C}\right)$ for at least $12 \mathrm{~h}$ before being placed in the standard capillary absorption setup. Throughout the absorption tests, the immersion depth was kept constant at $2 \mathrm{~mm}$. The standard capillary absorption setup is schematically shown in Fig. 6 (b).

The capillary absorption coefficient was calculated based on Eq. 1, from the slope of the absorption versus square root of time in both cracked and uncracked states. 


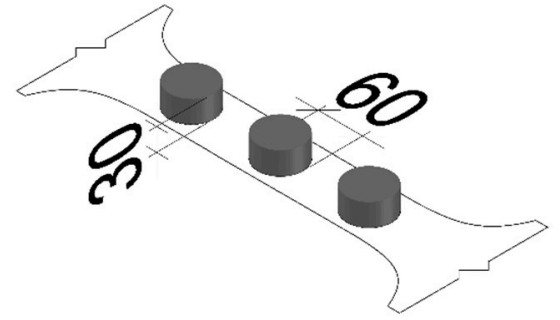

(a)

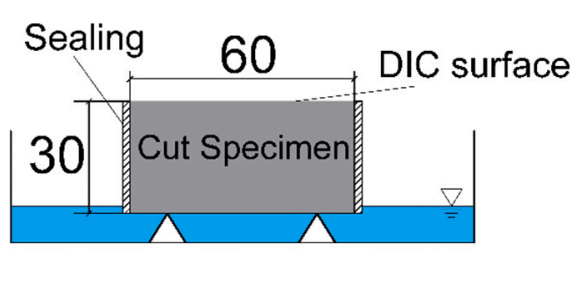

(b)

Fig. 6. Dimensions and location of the cores extracted from the dumbbell specimen (a) and, a schematic sketch of standard capillary absorption setup (b) (dimensions in $\mathrm{mm}$ ).

Table 3

Overview of the performed tests.

\begin{tabular}{|c|c|c|c|c|}
\hline $\begin{array}{l}\text { Specimen } \\
\text { no. }\end{array}$ & $\begin{array}{l}\text { Loaded } \\
\text { until }\end{array}$ & $\begin{array}{l}\text { Capillary } \\
\text { absorption } \\
\text { under tension }\end{array}$ & $\begin{array}{l}\text { Capillary } \\
\text { absorption } \\
\text { after unloading }\end{array}$ & \\
\hline 1 & $\begin{array}{l}\text { Ultimate } \\
\text { strain }\end{array}$ & - & - & $\begin{array}{l}\text { Tensile prop. \& } \\
\text { crack char. }\end{array}$ \\
\hline 2 & $\begin{array}{l}\text { Ultimate } \\
\text { strain }\end{array}$ & - & - & \\
\hline 3 & $\begin{array}{l}\text { Ultimate } \\
\text { strain }\end{array}$ & - & - & \\
\hline 4 & $0.015 \%$ & $3 \times$ chambers & - & Serviceability \\
\hline 5 & $0.03 \%$ & $3 \times$ chambers & - & domain \\
\hline 6 & $0.05 \%$ & $3 \times$ chambers & $3 \times$ cylinders & \\
\hline 7 & $0.05 \%$ & $3 \times$ chambers & - & \\
\hline 8 & $0.1 \%$ & $3 \times$ chambers & $3 \times$ cylinders & \\
\hline 9 & $0.15 \%$ & $3 \times$ chambers & $3 \times$ cylinders & \\
\hline 10 & $0.2 \%$ & $3 \times$ chambers & $3 \times$ cylinders & \\
\hline 11 & $1 \%$ & $3 \times$ chambers & $3 \times$ cylinders & Large \\
\hline 12 & $2 \%$ & $3 \times$ chambers & $3 \times$ cylinders & deformation \\
\hline
\end{tabular}

$i=S . t^{0.5}$

where $i$ is the cumulative absorption, $t$ is time, and $S$ is a constant referred as the sorptivity (capillary absorption coefficient).

It should be born in mind that original UHPFRC made with a majority of reactive powders have a very low degree of hydration, due to their very low $\mathrm{w} / \mathrm{b}$ ratio $[52,53]$. Thus, delayed hydration of the unhydrated binders when the material is in contact with water during permeability tests over several weeks may influence results, and require the use of different liquids not reacting with cement [27]. However, this effect was neglected in this study as the exposure time to water was short

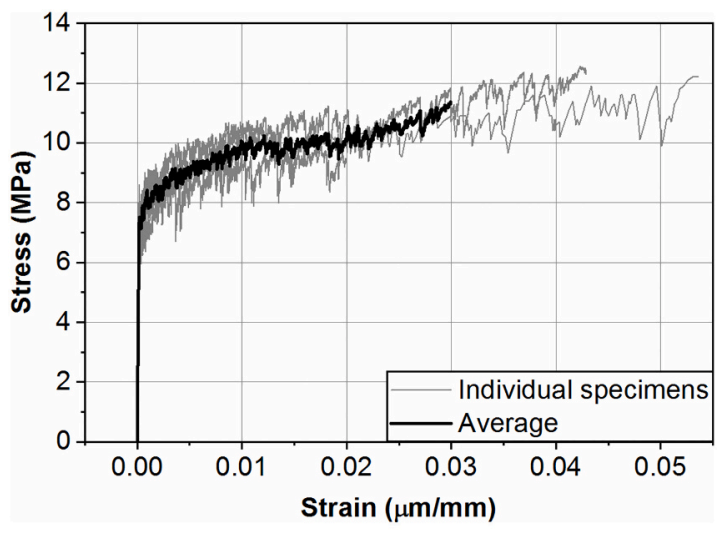

(a) and also the amount of unhydrated binders was significantly lower for the investigated PE-UHPFRC compared with conventional mixes, because of the replacement of $50 \%$ of the clinker by limestone filler. The maximum degree of hydration for PE-UHPFRC was $52 \%$ and $60 \%$, after Waller [54] and Jensen [55] models, respectively.

\subsection{Overview of performed tests}

Table 3 gives an overview of all the performed tests. Three uniaxial tensile tests until the end of hardening were performed in order to characterize the tensile behavior of the material. Capillary absorption tests were carried out on the specimens for a wide range of tensile strain levels. The investigated strain levels are $0.015 \%, 0.03 \%, 0.05 \%, 0.1 \%$, $0.15 \%, 0.2 \%, 1 \%$ and $2 \%$. First, the specimens were loaded to the defined strain levels, measuring the strain with the help of two LVDTs with the gauge length of $515 \mathrm{~mm}$ (Fig. 4). Meanwhile, the crack characteristics were recorded by means of DIC. Afterward, the chambers were installed on the surface of the specimens and the capillary absorption measurement started. Considering the effect of saturation conditions on the capillary absorption, a separate specimen was tested for each strain level. Repetition was done for the strain level of $0.05 \%$ to characterize the variability of the obtained results.

\section{Results and discussion}

\subsection{Tensile response and evolution of damage under tension}

The uniaxial tensile test results of all the tested specimens are shown in Fig. 7. The $x$-axis shows the average tensile strain computed from the extensions of two pilot LVDT that controlled the deformation with the gage length of $515 \mathrm{~mm}$ (setup shown in Fig. 4).

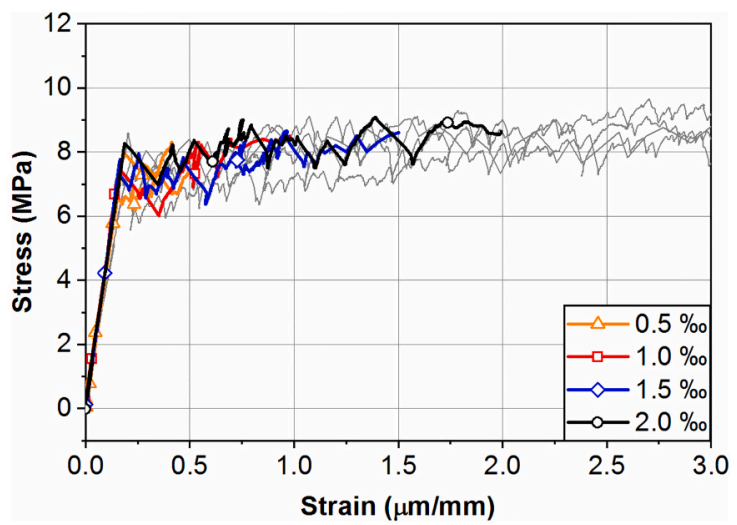

(b)

Fig. 7. Uniaxial tensile stress-strain response of the tested PE-UHPFRC specimens (a) zoom until $0.3 \%$ strain level (b). 


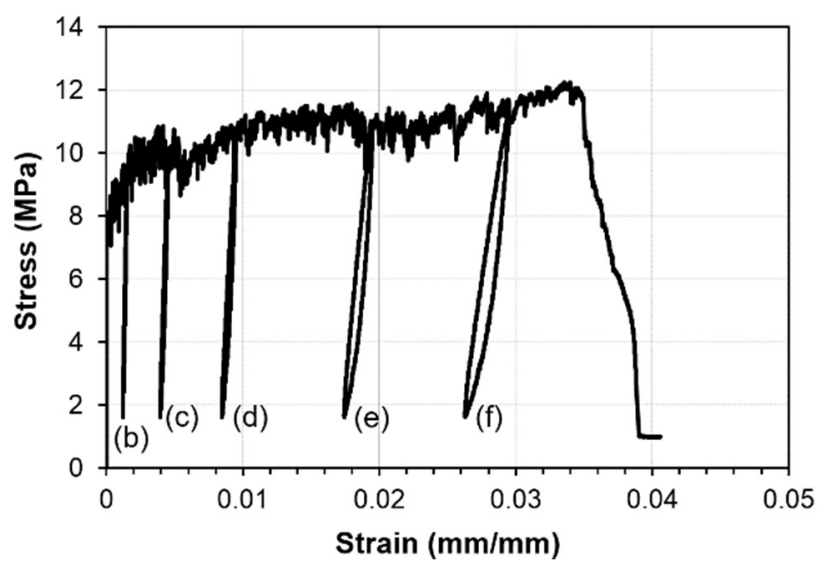

(a)

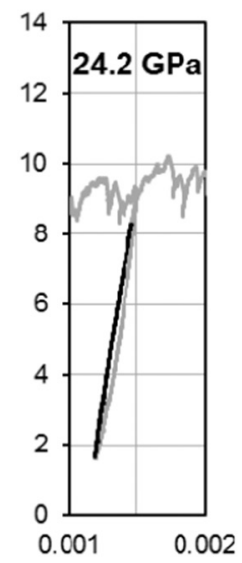

(b)

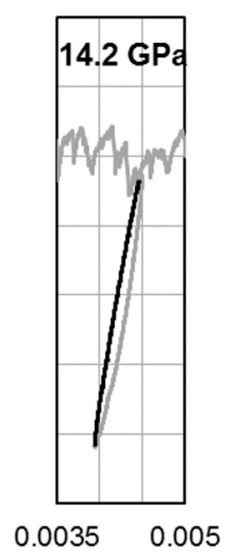

(c)

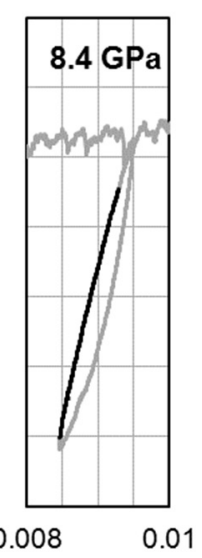

(d)

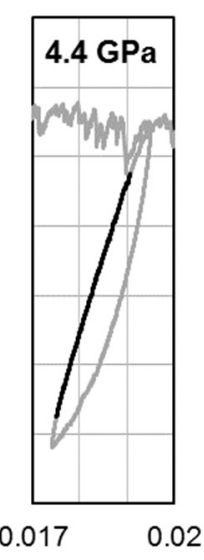

(e)

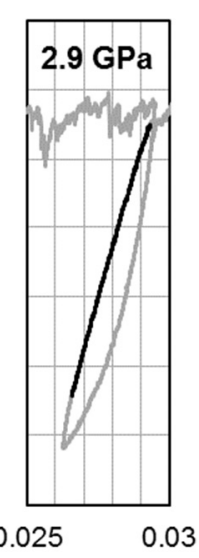

(f)

Fig. 8. Unloading-loading cycles and apparent E modulus of a tensile specimen at different strain levels.

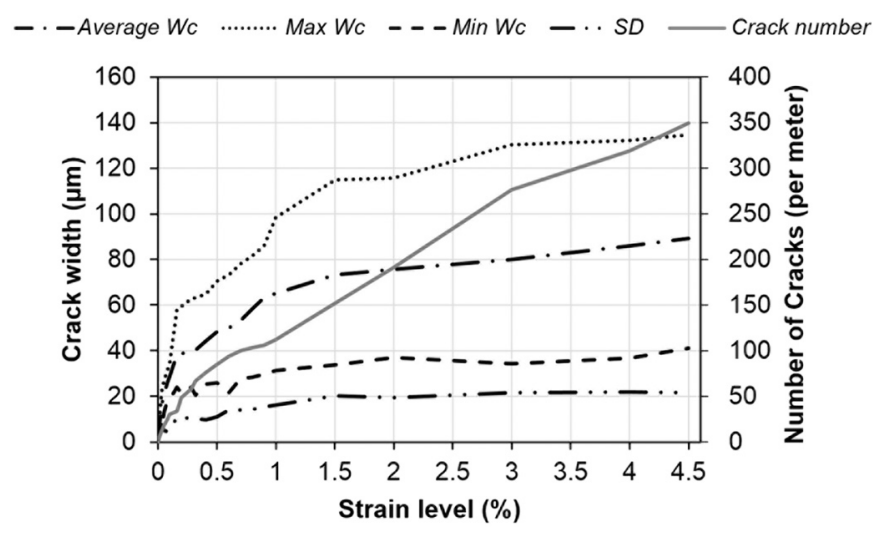

Fig. 9. Crack number, and average, maximum, minimum and standard deviation of the crack width under tension of specimen No. 2 .

The specimens had a strain-hardening behavior and numerous multiple cracks developed gradually. As it is shown in Fig. 7, the elastic limit (first crack strength) was above $7 \mathrm{MPa}$. The average elastic modulus of the material in tension was $43 \mathrm{GPa}$, which was computed from the slope of the average straight line through the stress-strain data points of the specimen. Furthermore, it should be noted that compared to other results from the literature [33], the stress fluctuation in the hardening zone was much lower. Fig. 7 highlights highly reproducible tensile test results which confirm the robustness of the material and the effectiveness of the testing setup.
The evolution of damage under tension is an important property, which can be characterized by determining the apparent $\mathrm{E}$ modulus at different tensile strains by performing unloading-loading cycles. Fig. 8 shows the unloading-loading cycles and the apparent $\mathrm{E}$ modulus of a tensile specimen at strain levels of $0.15,0.4,1,2$ and $3 \%$.

\subsection{Crack characteristics}

The crack characteristics were analyzed up to the strain level of $4.5 \%$. Considering the yield strain of approximately $0.2 \%$ for conventional steel reinforcement in structural members, $4.5 \%$ strain will never be reached under service loads in RC structures. However, investigating higher strains is still important to understand the full picture of the evolution of the cracks and of the associated capillary absorption. Fig. 9 shows the crack numbers, and average, maximum, minimum and standard deviation of the crack width $\left(w_{c}\right)$ for a uniaxial tensile test. The specimen exhibited a multiple cracking behavior and the average crack widths did not exceed $0.1 \mathrm{~mm}$ even up to a very high strain level of $4.5 \%$.

Fig. 10 shows the DIC images of the tensile specimen No. 2 at strain levels of $0.1,0.2,1,2,3$ and $4 \%$ along with the crack analysis. The horizontal lines indicate the crack location and the dots show the corresponding crack width. The gauge length of the strain $\varepsilon_{y y}$, which is represented by the colored contour plot, was 20 pixels, which was 1.43 $\mathrm{mm}$ in this study.

Fig. 11 represents the distribution of the crack width at the strain levels of 1, 2, 3 and $4 \%$. For the strain levels of 1 and $2 \%$, a lognormal distribution fits well on the results, as suggested in the literature for ECC and SHCC materials $[37,38,56]$. However, for the higher strain levels of 

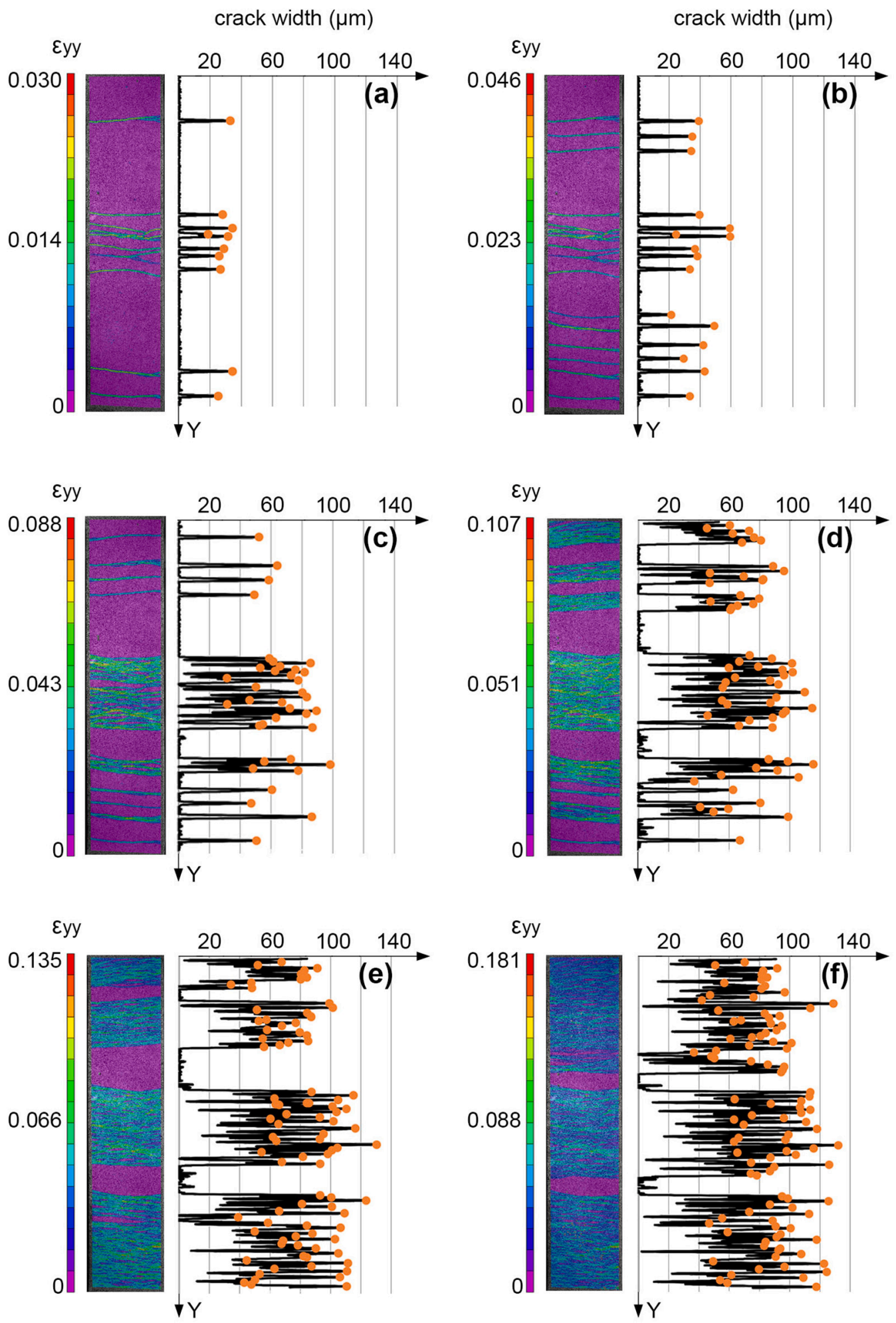

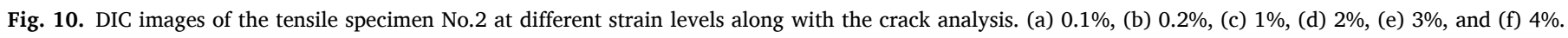

3 and $4 \%$, the distribution of the crack width was closer to a normal distribution, Fig. 11 (b).

Fig. 12 illustrates the crack width after unloading for a strain level of $4 \%$. As it is shown, the maximum crack width after unloading decreased significantly and reached below $0.05 \mathrm{~mm}$.

\subsection{Capillary absorption test under tension}

Fig. 13 shows the average water capillary absorption under tension from the three chambers, for the strain level of 0.015 to $0.2 \%$. Considering that the elastic limit of the material was around $0.02 \%$, the strain level of $0.015 \%$ was in the elastic domain and the specimen was still uncracked. The capillary absorption coefficient for this strain level was in the extremely low range of 3 to $4 \mathrm{~g} / \mathrm{m}^{2} \sqrt{\mathrm{h}}$ that confirms the very 


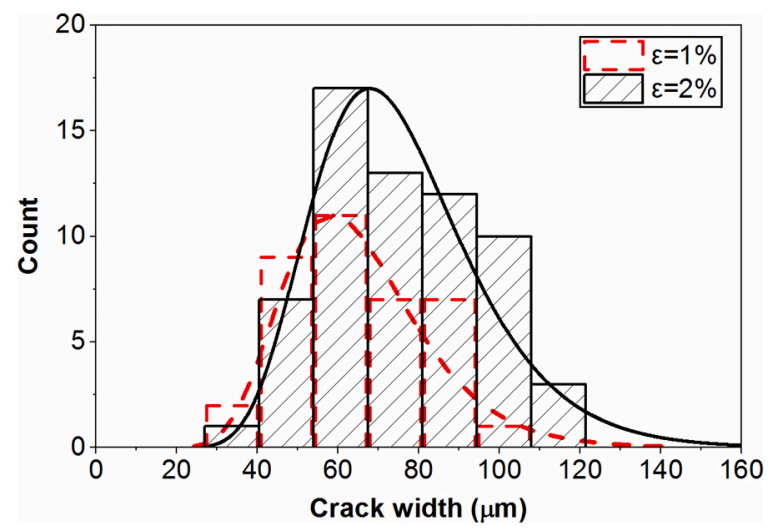

(a)

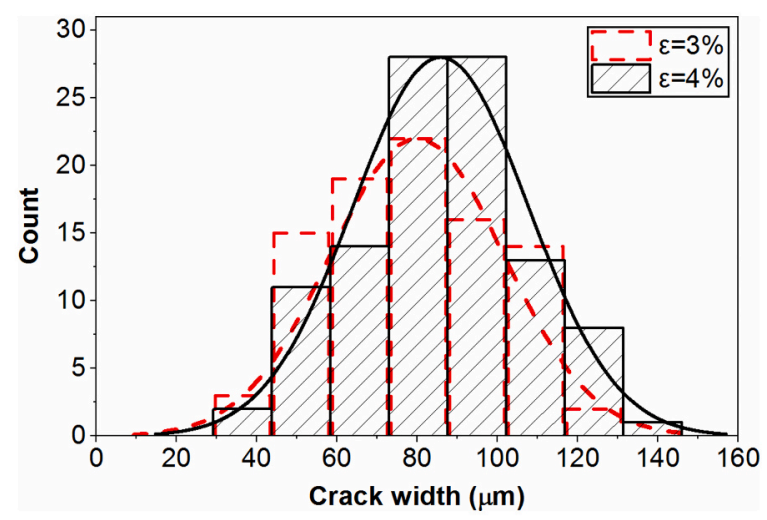

(b)

Fig. 11. Crack width distribution: (a) for 1 and $2 \%$ strain levels - lognormal distribution, and (b) for 3 and $4 \%$ strain levels - normal distribution.
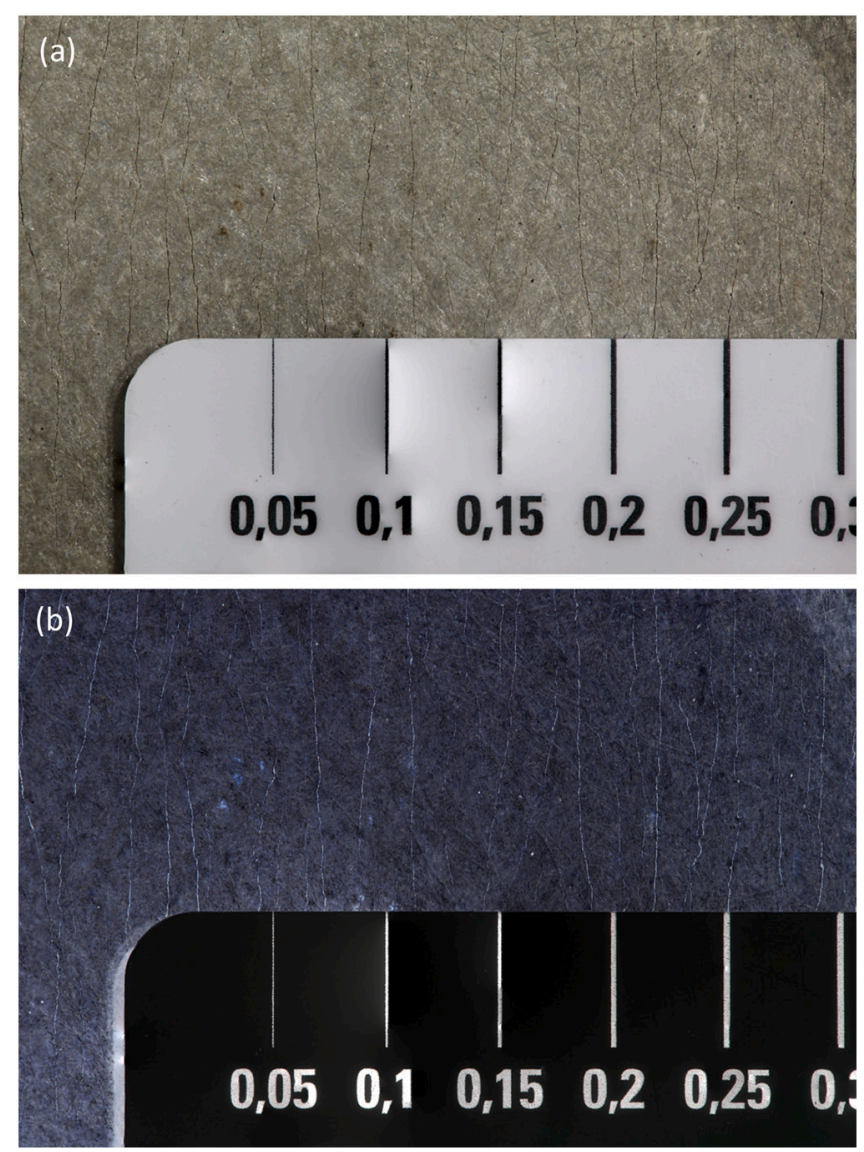

Fig. 12. Crack width after unloading for a strain level of $4 \%$, (a) normal and (b) inverted.

dense microstructure of the material. The strain level of $0.03 \%$ was just after the elastic limit at which there was only one crack on the specimen. Accordingly, only the chamber that was on the cracked area was showing higher values and the capillary absorption from the two other chambers remained close to $4 \mathrm{~g} / \mathrm{m}^{2} \sqrt{ } \mathrm{h}$.

Fig. 14 represents the crack patterns with respect to the location of the chambers as well as the crack widths for the strain levels of $0.05,0.1$, 0.15 and $0.2 \%$. In this figure, the positions of the cracks are outlined by dashed lines and the circles show the position of the chambers on the specimens. At the strain level of $0.05 \%$, two cracks with widths of 50.2

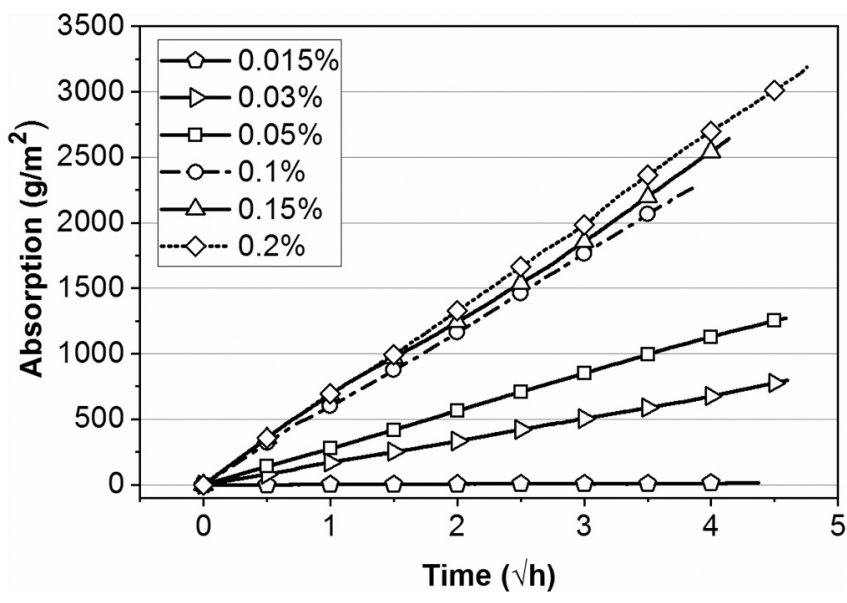

Fig. 13. Average water capillary absorption under tension, from three chambers for the strain levels of 0.015 to $0.2 \%$.

$\mu \mathrm{m}$ and $33.6 \mu \mathrm{m}$ along a length of $29.7 \mathrm{~mm}$ and $38.1 \mathrm{~mm}$, respectively, were present under the top chamber (A). One crack with a width of 38.8 $\mu \mathrm{m}$ along a length of $57.6 \mathrm{~mm}$ was present under the middle chamber (B). Finally, one crack with a width of $44 \mu \mathrm{m}$ along a length of $58.7 \mathrm{~mm}$ was present under the bottom chamber (C). The average capillary absorption coefficient at this strain level was 293 and $313 \mathrm{~g} / \mathrm{m}^{2} \sqrt{\mathrm{h}}$ for the first and the repeated specimen, respectively.

At the strain level of $0.1 \%$, two cracks were present under chamber A, while there was one crack each within the area of both the other chambers. According to Table 4 and Fig. 14, the widest crack with a width of $70.7 \mu \mathrm{m}$ highly influenced the capillary absorption in the top chamber while the other two chambers exhibited similar capillary absorption with a similar crack pattern.

For the strain level of $0.15 \%$, nine cracks with an average width of $34 \mu \mathrm{m}$ located under chamber A, and three cracks with an average width of $85 \mu \mathrm{m}$ under chamber B, had a similar effect on capillary absorption. The capillary absorption of the bottom chamber (C), which did not experience any crack in its area, remained close to $4 \mathrm{~g} / \mathrm{m}^{2} \sqrt{\mathrm{h}}$.

At the strain level of $0.2 \%$, more cracks developed on the top and bottom part of the specimen compared to the center. Six cracks were found under chamber A. However, the cracks were situated close to the end of the chamber and therefore their lengths which were in direct contact with water, were shorter compared to that for the other two chambers. Two cracks with widths of $40.1 \mu \mathrm{m}$ and $46.4 \mu \mathrm{m}$ were present under chamber C. Four cracks with the width range of 50 to $100 \mu \mathrm{m}$ were 
crack width $(\mu \mathrm{m})$
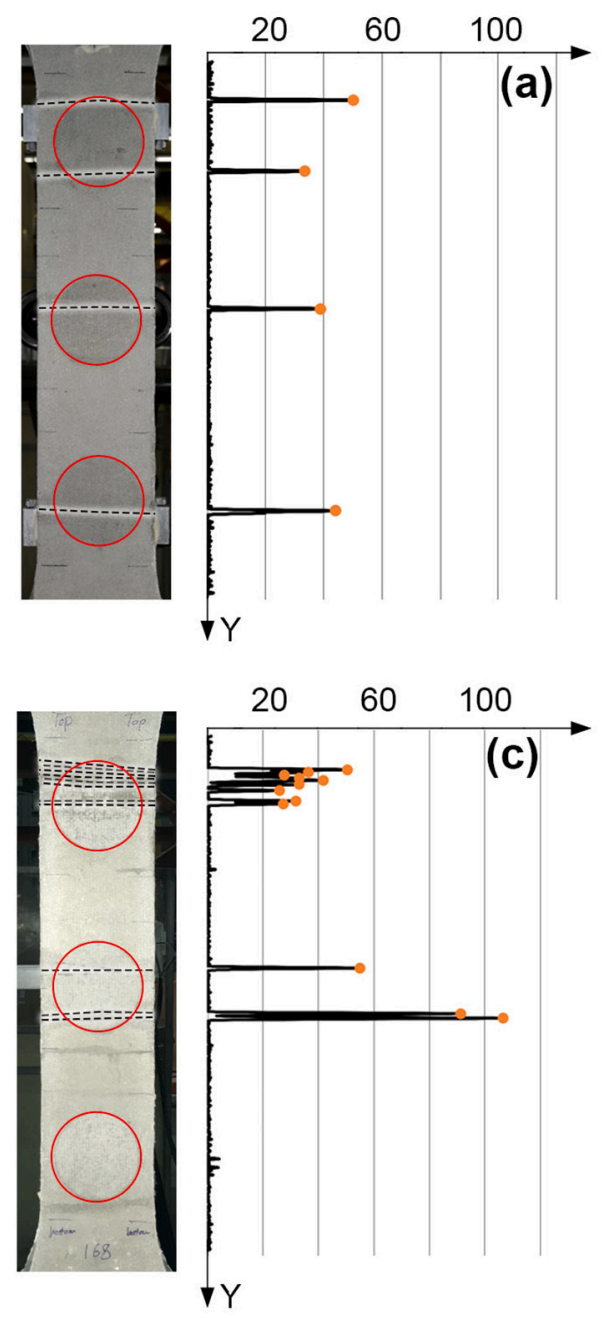

crack width $(\mu \mathrm{m})$
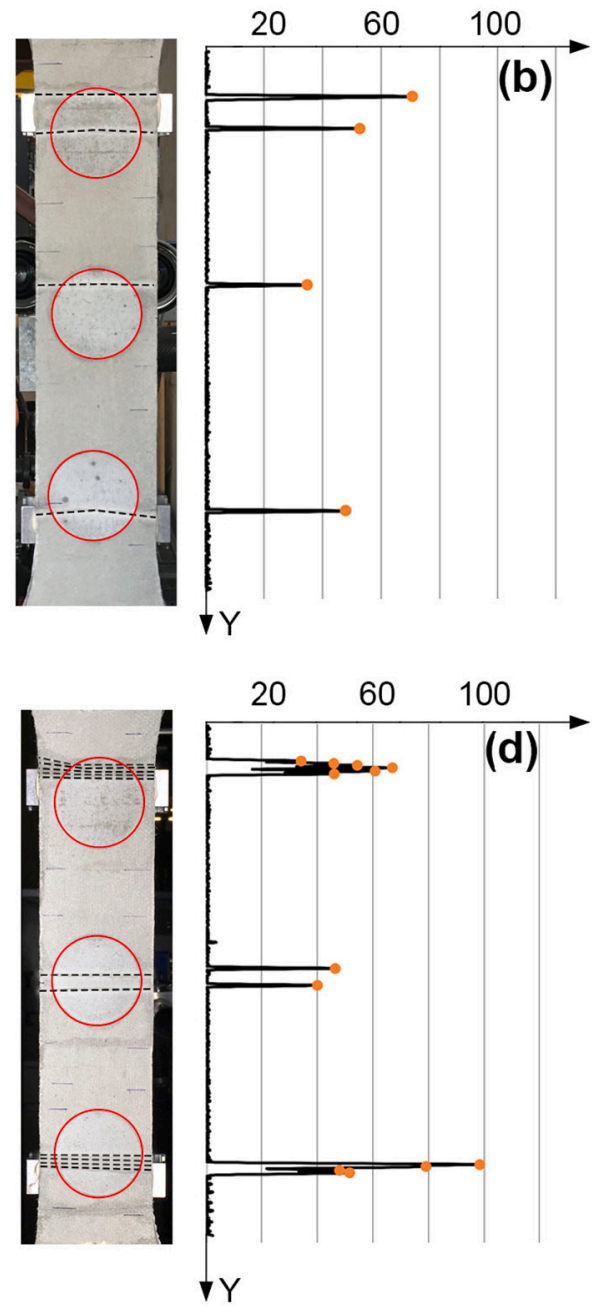

Fig. 14. Crack positions and the corresponding crack width for the specimens loaded up to strain levels of (a) $0.05 \%$, (b) $0.1 \%$, (c) $0.15 \%$ and (d) $0.2 \%$.

Table 4

Capillary absorption coefficients $\left(\mathrm{g} / \mathrm{m}^{2} \sqrt{\mathrm{h}}\right)$ under tension, from each chamber and the average values for strain levels of 0.03 to $2 \%$.

\begin{tabular}{|c|c|c|c|c|c|c|c|c|}
\hline Strain level & $0.03 \%$ & $0.05 \%$ & $0.05 \%$ & $0.1 \%$ & $0.15 \%$ & $0.2 \%$ & $1 \%$ & $2 \%$ \\
\hline Chamber A & 4 & 315 & 348 & 976 & 935 & 651 & 1612 & 4341 \\
\hline Chamber B & 502 & 314 & 300 & 390 & 932 & 689 & 1915 & 2682 \\
\hline Chamber C & 4 & 250 & 291 & 397 & 4 & 717 & 1659 & 3724 \\
\hline Average & 170 & 293 & 313 & 588 & 624 & 686 & 1729 & 3582 \\
\hline
\end{tabular}

present in the middle of the bottom chamber and resulted in a higher capillary absorption for this chamber.

Fig. 15 outlines the average water capillary absorption of the specimen from three chambers against the square root of hour, for the strain levels of 1 and $2 \%$, under tensile loading. At $1 \%$ strain level, the specimen experienced 38 cracks along a length of $354.5 \mathrm{~mm}$, which represents a crack density of 107 cracks per meter. The average of the crack width was $68.5 \mu \mathrm{m}$ with a standard deviation of 17.4. The capillary absorption coefficient of the specimen varied from 1600 to $1900 \mathrm{~g} /$ $\mathrm{m}^{2} \sqrt{\mathrm{h}}$ for the three chambers.

The crack density at the $2 \%$ strain level was 236 cracks per meter with the average crack width of $68.2 \mu \mathrm{m}$ and a standard deviation of 18.7. With respect to the crack characteristics at $1 \%$ strain level, the number of cracks increased by a factor of two, while the average crack width and standard deviation remained in a similar range. The average capillary absorption coefficient for the three chambers at a $2 \%$ strain level was $3582 \mathrm{~g} / \mathrm{m}^{2} \sqrt{ } \mathrm{h}$. This is a very high value comparable with the capillary absorption coefficient of red brick that is approximately 4000 $\mathrm{g} / \mathrm{m}^{2} \sqrt{\mathrm{h}}$.

The capillary absorption coefficient was calculated for each individual chamber and is shown in Table 4 for the strain levels of 0.03 to $2 \%$. The variation of the capillary absorption from different chambers at the strain levels below $0.2 \%$ is the result of a limited number of cracks and consequently non-uniform crack patterns at those strain levels. At the strain level of $0.03 \%$, there was only one crack on the specimen under the chamber B. Similarly, as it is shown in Fig. 14, there was no crack under the chamber $C$ at the strain level of $0.15 \%$.

In order to highlight the effect of cracks on capillary absorption, Fig. 16 shows the capillary absorption as a function of crack area for the specimen tested at $0.05,0.1,0.15$ and $0.2 \%$ strain level. In this figure, each point corresponds to one chamber and the crack area was calculated by the sum of the crack widths times crack lengths under the 


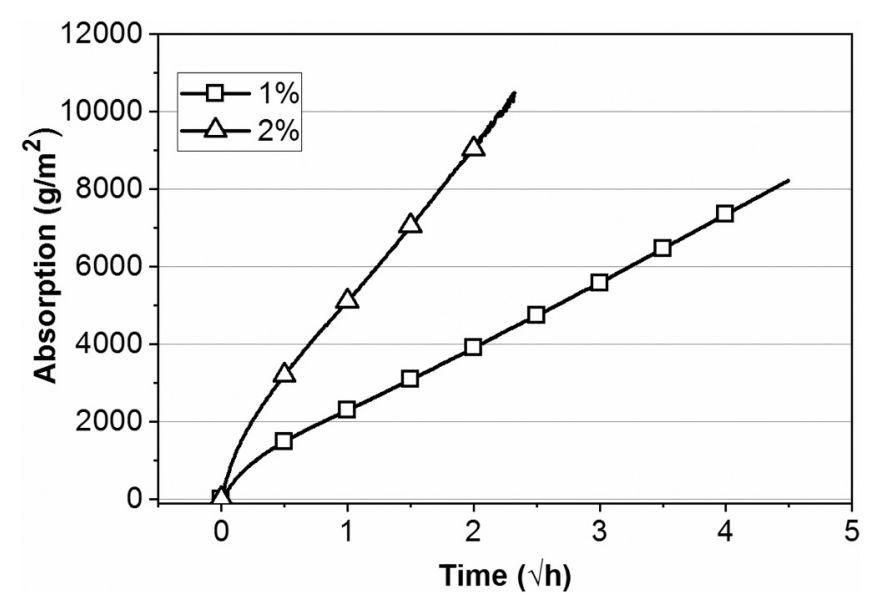

Fig. 15. Average of water capillary absorption under tension, from three chambers for the strain levels of 1 and $2 \%$.

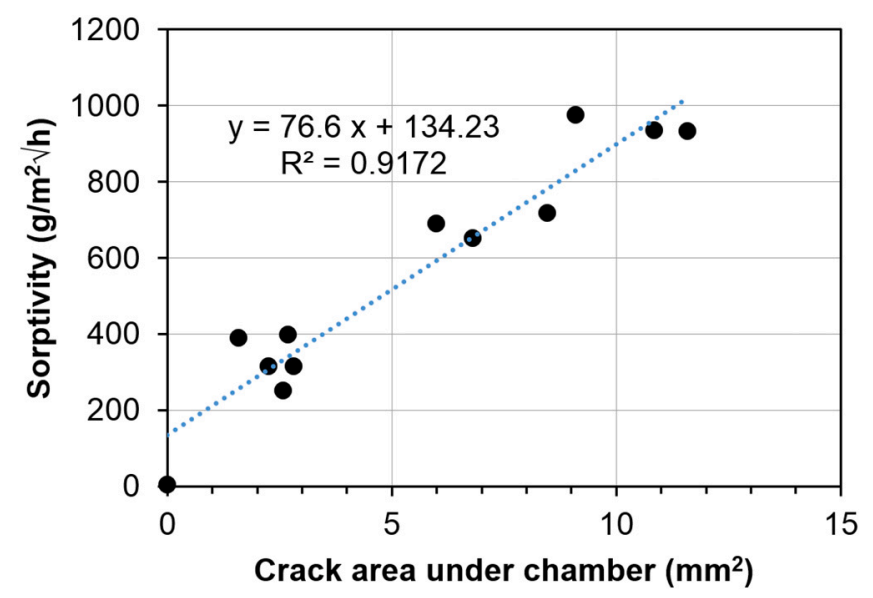

Fig. 16. Capillary absorption as a function of the crack area until the strain level of $0.2 \%$.

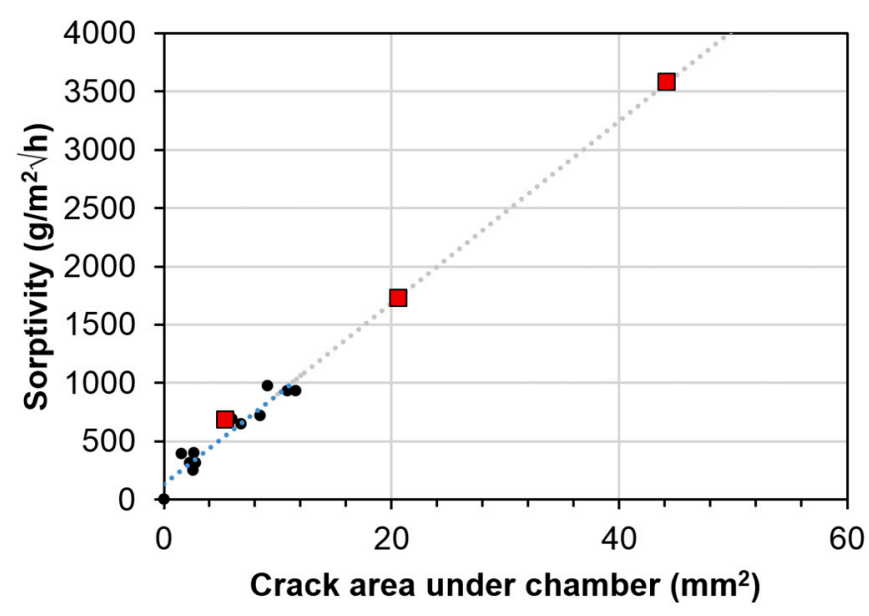

Fig. 17. Validation of the averaging method.

chamber. The results showed a linear relation relationship between the capillary absorption and the crack area.

In order to validate the averaging method used for reporting the capillary absorption at different strain levels, the average capillary absorption at strain levels of $0.2,1$, and $2 \%$ from Table 4 were plotted in
Fig. 17 versus the crack area calculated based on Fig. 9 and were compared with the linear relationship calculated in Fig. 16. The results fitted well on the linear relationship which confirmed both the validity of the averaging method and the crack information provided in Fig. 9.

\subsection{Capillary absorption test after unloading}

Specimen for capillary absorption tests after unloading were cored out of the dumbbell specimens for strain levels of $0.05 \%, 0.1 \%, 0.15 \%$, $0.2 \%, 1 \%$ and $2 \%$. Fig. 18 shows the average absorption of three cores, which were taken from each specimen after unloading on the same locations as that of the respective chambers A, B, C. The capillary absorption increased gradually with increasing strain levels. Although there was a linear correlation between capillary absorption and the square root of time for the lower strain levels (0.05 and $0.1 \%$ ), the relation deviated from linearity at the higher strain levels. This can be explained by the contrary effect of gravity on the capillary rise in the wider cracks which takes place for the configuration of the test after EN13057:2002 [45] (soaking from bottom face).

Table 5 presents the capillary absorption coefficient of the specimens that were tested after unloading (individual results and average), for the investigated strain levels.

\subsection{Discussion}

Fig. 19 compares the capillary absorption of PE-UHPFRC with that of SHCC under various strain levels, taken from Mechtcherine et al. [36] and Wittmann et al. [43]. In this figure, the capillary absorption coefficient of PE-UHPFRC is the average of three values. In all the cases, the specimen is damaged under tension and the capillary absorption test is performed on the cores from the tensile specimen after unloading.

It can be noticed from Fig. 19 that the water capillary absorption of PE-UHPFRC is at least one order of magnitude lower than that of SHCC. This highlights the fact that although crack width limitation criteria are a necessary condition for durability, the density of the microstructure plays an equally important role on transport properties and thereupon on the durability of the material. Moreover, as it can be seen in this figure, even after experiencing the strain level of $2 \%$, after unloading, the absorption coefficient of PE-UHPFRC is lower than that of undamaged normal concrete, which is in the range of $300 \mathrm{~g} / \mathrm{m}^{2} \sqrt{\mathrm{h}}$.

The influence of imposed tensile stresses on capillary absorption of UHPFRC with steel fibers under tensile loading has been investigated by Wittmann et al. [24]. Tensile test results for the same material are presented in [57]. On this basis and considering a typical range of strain levels corresponding to elastic limits of PE-UHPFRC from 0.015 to $0.02 \%$, Fig. 20 shows a sudden increase in capillary absorption coefficients after the elastic limit. A similar trend was observed for the PEUHPFRC.

Moreover, the capillary absorption coefficient of steel fiber UHPFRC decreases by approximately $35 \%$ after unloading while according to Fig. 21, the capillary absorption of PE-UHPFRC decreases at least 10 times after unloading. This can be explained by different crack closure behaviors of these two materials after unloading. The stiffness of steel fibers hinders the closure of cracks, while synthetic fiber can hardly oppose to crack closure after unloading.

The durability related requirements for the Serviceability Limit State (SLS) depend on both material properties and the expected service life of the structure. Considering that the expected service life for UHPFRC applications is the full service life of the structure without any further rehabilitation, the UHPFRC layer should remain impermeable during the whole remaining service life of the structure after rehabilitation, to fulfill the SLS criteria. The French standard on UHPFRC [58] followed the normal and fiber-reinforced concrete codes [59] and recommended limitations on the maximum crack width for the durability related SLS. However, this approach is questionable according to the results of this study and other investigations reported in the literature [24,60]. As 


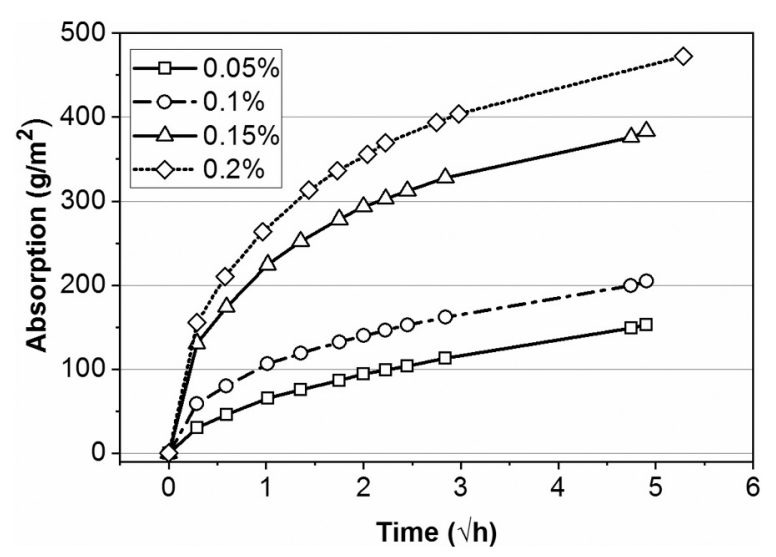

(a)

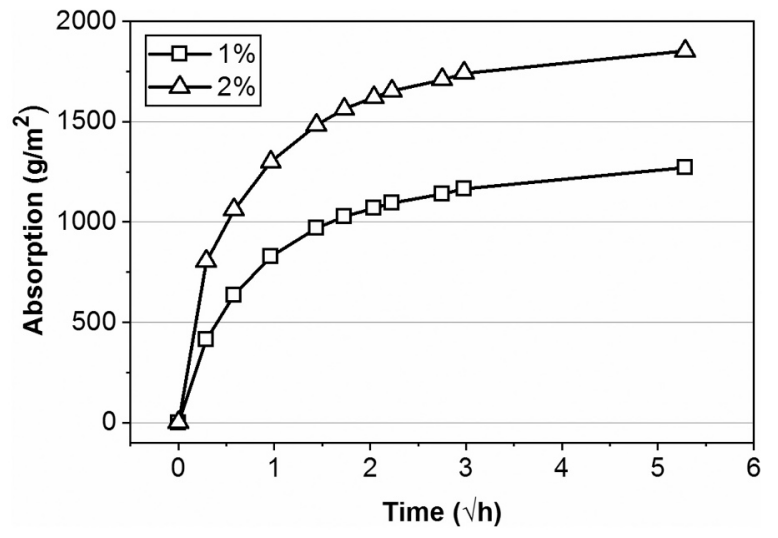

(b)

Fig. 18. Average of water capillary absorption test results from three cores, for the strain levels of (a) 0.05 to $0.2 \%$, and (b) 1 and $2 \%$, after unloading.

Table 5

Capillary absorption coefficients $\left(\mathrm{g} / \mathrm{m}^{2} \sqrt{ } \mathrm{h}\right)$ for tests after unloading, from each core and the average values for strain level of 0.05 to $2 \%$.

\begin{tabular}{lllllrl}
\hline Strain level & $0.05 \%$ & $0.1 \%$ & $0.15 \%$ & $0.2 \%$ & $1 \%$ & $2 \%$ \\
\hline Core A & 25 & 46 & 87 & 57 & 203 & 142 \\
Core B & 24 & 18 & 53 & 48 & 186 & 211 \\
Core C & 25 & 22 & 5 & 77 & 75 & 224 \\
Average & 25 & $\mathbf{2 9}$ & $\mathbf{4 8}$ & $\mathbf{6 1}$ & $\mathbf{1 5 5}$ & $\mathbf{1 9 2}$ \\
\hline
\end{tabular}

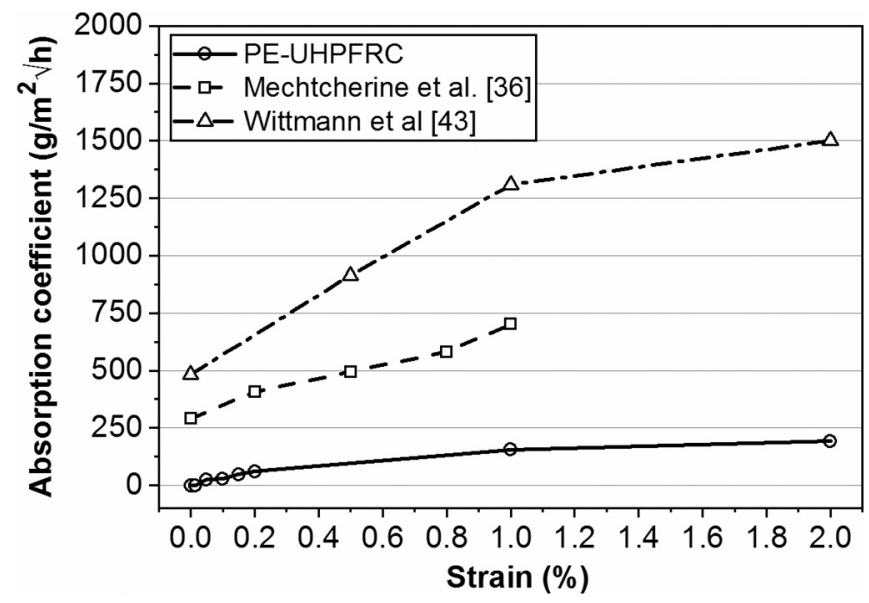

Fig. 19. Comparison between capillary absorption coefficient of PE-UHPFRC, and SHCC at different strain level after unloading.

such, in order to provide proper protective function throughout the entire lifetime of the structure, the PE-UHPFRC layer should stay uncracked. Thus, the sum of the tensile stresses in a PE-UHPFRC layer from internal and external action effects should remain below the tensile elastic limit of the material at SLS, from a purely local, deterministic point of view. However, further investigations should be carried out to generalize these findings to the determination of Serviceability Limit States for Strain Hardening UHPFRC in structural members considering the deterioration mechanisms followed by the ingress of liquids through microcracks in UHPFRC, with or without rebar.

\section{Conclusions}

The effect of the strain level on the capillary absorption of water in

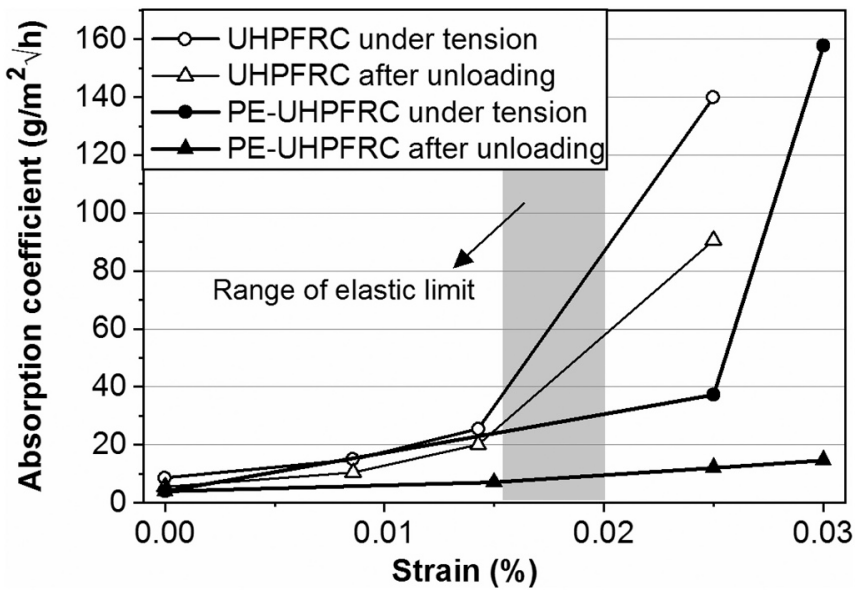

Fig. 20. Capillary absorption of UHPFRC with steel fibers and PE-UHPFRC versus strain level.

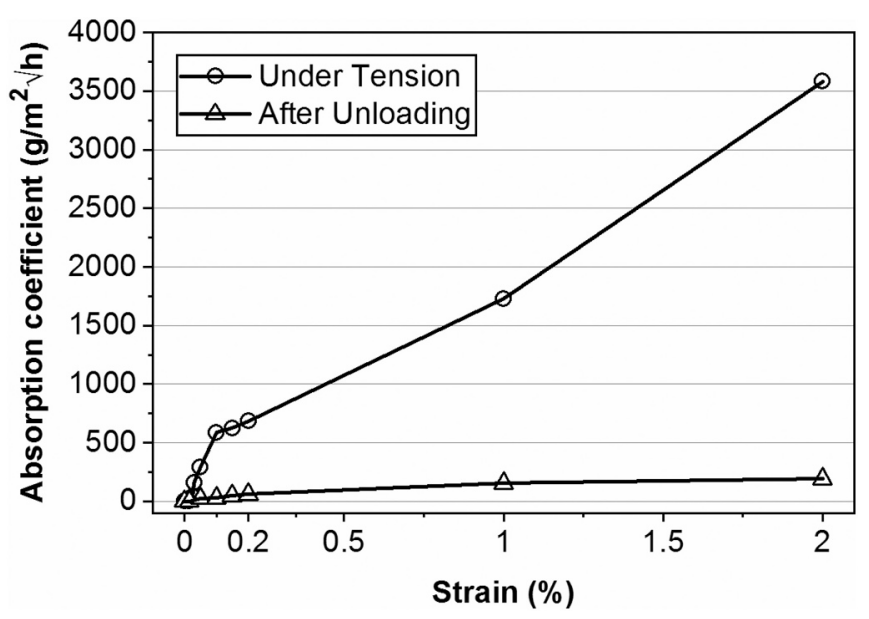

Fig. 21. Average capillary absorption coefficient of the PE-UHPFRC versus strain level.

PE-UHPFRC was investigated in two ways: (I) under tension, using an original testing setup, and (II) after unloading, based on standards. According to the results, 
- The cracking behavior of PE-UHPFRC was similar to that of other cementitious materials with high deformation capacity (ECC and SHCC), up to a strain level of $2 \%$, and the cracks width similarly followed a lognormal distribution. The average crack width remained below $0.1 \mathrm{~mm}$ throughout the tensile behavior. However, for higher strain levels ( 3 and 4\%), the crack width distribution changed towards a normal distribution.

- The capillary absorption of PE-UHPFRC after unloading was at least ten times less than that of SHCC, which is a comparable cementitious materials in terms of deformation capacity, at all the studied strain levels.

- There was a sudden significant increase in capillary absorption of UHPFRC (including literature) after the elastic limit under tensile loading.

- The capillary absorption of damaged PE-UHPFRC after unloading increased gradually with the strain level, and remained below 60.9 $\mathrm{g} / \mathrm{m}^{2} \sqrt{\mathrm{h}}$ even after experiencing a strain level of $0.2 \%$ before unloading.

- There was a considerable difference of approximately one order of magnitude in the rate of liquid ingress, when comparing the capillary absorption of same PE-UHPFRC samples, under tension and after unloading. This highlights the necessity of developing more realistic test methods in order to define the durability properties and serviceability limit state of cementitious materials with high deformation capacity.

- Although crack width limitation is a necessary condition for durability, the density of the microstructure of the material plays an equally important role on transport properties and thereupon on its durability and protective properties.

- Fixing threshold values of crack width for durability must be done considering the relevant transport mechanisms.

\section{CRediT authorship contribution statement}

A. Hajiesmaeili1, E. Denarié2.

1 - corresponding author, conducted all the experiments presented in the paper along with the writing of the full article.

2 - thesis supervisor.

\section{Declaration of competing interest}

The authors declare no conflict of interest.

\section{Acknowledgments}

This project is financially supported by the Swiss National Science Foundation (grant 407040_154063/1) through the National Research Program "Energy Turnaround" (NRP 70). The authors would like to gratefully acknowledge Dyneema, Omya, LafargeHolcim, and Sika for donating the PE fiber, limestone filler, cement, and superplasticizer respectively. The authors also would like to acknowledge Serge Despont and Gilles Guignet, technicians at GIS/EPFL, for their help regarding the preparation of test setups, DIC measurements, and performing the tests.

\section{References}

[1] E. Denarié, M. Kazemi Kamyab, E. Brühwiler, B.G. Haddad, S. Nendaz, Béton fibré ultra performant pour la maintenance, un nouvel élan, Tracés $N^{\circ} 12$. (2011) 20-23.

[2] E. Brühwiler, E. Denarié, Rehabilitation and strengthening of concrete structures using ultra-high performance fibre reinforced concrete, Structural Engineering International: Journal of the International Association for Bridge and Structural Engineering (IABSE). 23 (2013) 450-457, https://doi.org/10.2749/ $101686613 \times 13627347100437$.

[3] E. Denarié, E. Brühwiler, Cast-on site UHPFRC for improvement of existing structures-achievements over the last 10 years in practice and research, 7th Workshop on High Performance Fiber Reinforced Cement Composites, 1-3, June 2015, Germany, Stuttgart, 2015.

[4] A. Hajiesmaeili, E. Denarie, Next Generation UHPFRC for Sustainable Structural Applications, ACI Special Publication. 326 (2018).
[5] C. Hall, Water movement in porous building materials-I. Unsaturated flow theory and its applications, Building and Environment. 12 (1977) 117-125. doi: https://doi.org/10.1016/0360-1323(77)90040-3.

[6] R. Lucas, Rate of capillary ascension of liquids, Kolloid Z. 23 (1918) 15-22.

[7] E.W. Washburn, The dynamics of capillary flow, Phys. Rev. 17 (1921) 273.

[8] J. Bao, L. Wang, Capillary imbibition of water in discrete planar cracks, Constr. Build. Mater. 146 (2017) 381-392, https://doi.org/10.1016/j. conbuildmat.2017.04.129.

[9] D. Gardner, A. Jefferson, A. Hoffman, Investigation of capillary flow in discrete cracks in cementitious materials, Cem. Concr. Res. 42 (2012) 972-981, https://doi. org/10.1016/j.cemconres.2012.03.017.

[10] D. Gardner, A. Jefferson, A. Hoffman, R. Lark, Simulation of the capillary flow of an autonomic healing agent in discrete cracks in cementitious materials, Cem. Concr. Res. 58 (2014) 35-44, https://doi.org/10.1016/j.cemconres.2014.01.005.

[11] Y.A.V. Zaccardi, N.M. Alderete, N. De Belie, Improved model for capillary absorption in cementitious materials: Progress over the fourth root of time, Cem. Concr. Res. 100 (2017) 153-165.

[12] H. Huang, X. Gao, H. Wang, H. Ye, Influence of rice husk ash on strength and permeability of ultra-high performance concrete, Constr. Build. Mater. 149 (2017) 621-628, https://doi.org/10.1016/j.conbuildmat.2017.05.155.

[13] S. Pyo, H.K. Kim, Fresh and hardened properties of ultra-high performance concrete incorporating coal bottom ash and slag powder, Constr. Build. Mater. 131 (2017) 459-466, https://doi.org/10.1016/j.conbuildmat.2016.10.109.

[14] D. Dobias, R. Pernicova, T. Mandlik, Water Transport properties and depth of chloride penetration in ultra high performance concrete, in: Key Engineering Materials, Trans Tech Publ, 2016: pp. 137-142.

[15] W. Wang, J. Liu, F. Agostini, C.A. Davy, F. Skoczylas, D. Corvez, Durability of an ultra high performance fiber reinforced concrete (UHPFRC) under progressive aging, Cem. Concr. Res. 55 (2014) 1-13, https://doi.org/10.1016/j. cemconres.2013.09.008.

[16] C.M. Tam, V.W.Y. Tam, K.M. Ng, Assessing drying shrinkage and water permeability of reactive powder concrete produced in Hong Kong, Constr. Build. Mater. 26 (2012) 79-89, https://doi.org/10.1016/j.conbuildmat.2011.05.006.

[17] D. Mestrovic, D. Cizmar, V. Stanilovic, Reactive powder concrete: material for the 21st century, WIT Trans. Eng. Sci. 57 (2007) 127-133, https://doi.org/10.2495/ MC070131.

[18] N. Roux, C. Andrade, A. Sanjuan M, Experimental study of durability of reactive powder concretes, Journal of Materials in Civil Engineering. 8 (1996) 1-6. doi: https://doi.org/10.1061/(ASCE)0899-1561(1996)8:1(1).

[19] F. Toutlemonde, P. Roenelle, Z. Hajar, A. Simon, R. Lapeyrère, R.-P. Martin, S. Ramanich, L. Baron, Long-term material performance checked on world's oldest UHPFRC road bridges at Bourg-Lès-Valence, in: RILEM-Fib-AFGC International Symposium on UHPFRC, 2013: pp. 265-274.

[20] F. Toutlemonde, V. Bouteiller, G. Platret, M. Carcasses, M. Lion, F. Toutlemonde, Field demonstration of UHPFRC durbility, Concr. Int. 32 (2010) 39-45.

[21] A. Sajna, E. Denarié, V. Bras, Assessment of UHPFRC based bridge rehabilitation in Slovenia, two years after application, in: M. Schmidt, E. Fehling, C. Glotzbach, S. Fröhlich, S. Piotrowski (Eds.), Proceedings HIPERMAT 2012, 3rd International Symposium on Ultra-High Performance Concrete, Uni Kassel, Kassel, Germany, 2012, pp. 937-944.

[22] K. Kono, H. Musha, T. Kawaguchi, A. Eriguchi, S. Tanaka, T. Kobayashi, M. Ikeda, Durability study of the first PC bridge constructed with ultra high strength fiber reinforced concrete in Japan, in: Proceedings of the RILEM-Fib-AFGC International Symposium on Ultra-High Performance Fibre-Reinforced Concrete, 2013: pp. $239-248$.

[23] M. Thomas, B. Green, E. O'Neal, V. Perry, S. Hayman, A. Hossack, Marine performance of UHPC at Treat Island, in: Proceedings of the 3rd International Symposium on UHPC and Nanotechnology for High Performance Construction Materials, Kassel, Germany, Uni Kassel, Kassel, Germany, 2012, pp. 365-370.

[24] F.H. Wittmann, X. Yao, P. Wang, P. Zhang, T. Zhao, Influence of an imposed tensile stress and subsequent self-healing on capillary absorption and chloride penetration into HPFRCC, in: Seventh International RILEM Workshop on High Performance Fiber Reinforced Cement Composites (HPFRCC7), Germany, Stuttgart, 2015, pp. 251-258.

[25] R. Wang, X. Gao, Q. Li, Y. Yang, Influence of splitting load on transport properties of ultra-high performance concrete, Constr. Build. Mater. 171 (2018) 708-718, https://doi.org/10.1016/j.conbuildmat.2018.03.174.

[26] P. Wang, X. Yao, F.H. Wittmann, P. Zhang, T. Zhao, Influence of imposed compressive stress and subsequent self-healing on capillary absorption and chloride penetration into UHPFRCC, in: Seventh International RILEM Workshop on High Performance Fiber Reinforced Cement Composites (HPFRCC7), Germany, Stuttgart, 2015, pp. 243-250.

[27] J.-P. Charron, E. Denarié, E. Brühwiler, Transport properties of water and glycol in an ultra high performance fiber reinforced concrete (UHPFRC) under high tensile deformation, Cem. Concr. Res. 38 (2008) 689-698, https://doi.org/10.1016/j. cemconres.2007.12.006.

[28] Z. Ma, T. Zhao, X. Yao, Influence of applied loads on the permeability behavior of ultra high performance concrete with steel fibers, J. Adv. Concr. Technol. 14 (2016) 770-781, https://doi.org/10.3151/jact.14.770.

[29] Y. Li, K.H. Tan, E.-H. Yang, Influence of aggregate size and inclusion of polypropylene and steel fibers on the hot permeability of ultra-high performance concrete (UHPC) at elevated temperature, Constr. Build. Mater. 169 (2018) 629-637, https://doi.org/10.1016/j.conbuildmat.2018.01.105.

[30] J.-P. Charron, E. Denarié, E. Brühwiler, Permeability of ultra high performance fiber reinforced concretes (UHPFRC) under high stresses, Mater. Struct. 40 (2007) 269-277, https://doi.org/10.1617/s11527-006-9105-0. 
[31] V.C. Li, On engineered cementitious composites (ECC), J. Adv. Concr. Technol. 1 (2003) 215-230.

[32] I. Curosu, M. Liebscher, V. Mechtcherine, C. Bellmann, S. Michel, Tensile behavior of high-strength strain-hardening cement-based composites (HS-SHCC) made with high-performance polyethylene, aramid and PBO fibers, Cem. Concr. Res. 98 (2017) 71-81.

[33] R. Ranade, V.C. Li, M.D. Stults, W.F. Heard, T.S. Rushing, Composite properties of high-strength, high-ductility concrete., ACI Materials Journal. 110 (2013).

[34] P.G. Wang, F.H. Wittmann, P. Zhang, E.H. Lehmann, T.J. Zhao, Observation of water penetration into cracked and water repellent SHCC after imposed strain by means of neutron radiography, Restoration of Buildings and Monuments. 20 (2014) 95-102.

[35] P. Zhang, F.H. Wittmann, B. Villmann, T.J. Zhao, V. Slowik, Moisture diffusion in and capillary suction of integral water repellent cement based materials, in: Proceedings of 5th International Conference on Water Repellent Treatment of Building Materials, Aedificatio Publishers, Brussels, Belgium, 2008, pp. 273-286.

[36] V. Mechtcherine, M. Lieboldt, Effect of cracking on air-permeability and water absorption of strain hardening cement-based composites, in: Proceedings, Fifth International RILEM Workshop on High Performance Fiber Reinforced Cement Composites (HPFRCC 5), 2007: pp. 305-312.

[37] W.P. Boshoff, C.J. Adendorff, Modelling SHCC cracking for durability, Fracture and Damage of Advanced Fibre-Reinforced Cement-Based Materials, Aedificatio Publishers, Dresden, 2010.

[38] W.P. Boshoff, F. Altmann, C.J. Adendorff, V. Mechtcherine, A new approach for modelling the ingress of deleterious materials in cracked strain hardening cementbased composites, Mater. Struct. 49 (2016) 2285-2295.

[39] M. Şahmaran, V.C. Li, Influence of microcracking on water absorption and sorptivity of ECC, Mater. Struct. 42 (2009) 593-603.

[40] M. Lepech, V.C. Li, Water permeability of cracked cementitious composites, Proceedings ICF11, 11th International Conference on Fracture, 2002.

[41] M.D. Lepech, V.C. Li, Water permeability of engineered cementitious composites, Cem. Concr. Compos. 31 (2009) 744-753.

[42] F.H. Wittmann, P. Wang, P. Zhang, T. Zhao, F. Beltzung, Capillary absorption and chloride penetration into neat and water repellent SHCC under imposed strain, in: 2nd International RILEM Conference on Strain Hardening Cementitious Composites (SHCC2-Rio), RILEM Publications SARL Rio de Janeiro, 2011: pp. 165-172.

[43] F.H. Wittmann, T. Zhao, L. Tian, F. Wang, L. Wang, Aspects of durability of strain hardening cement-based composites under imposed strain, in: G. Van Zijl, W.P. Boshoff (Eds.), Advances in Cement-based Materials, Taylor \& Francis Group, 2010: pp. 173-179.

[44] P. Zhang, F.H. Wittmann, T.J. Zhao, E.H. Lehmann, L. Tian, P. Vontobel, Observation and quantification of water penetration into strain hardening cement based composites (SHCC) with multiple cracks by means of neutron radiography,
Nuclear Instruments and Methods in Physics Research Section A: Accelerators, Spectrometers, Detectors and Associated Equipment. 620 (2010) 414-420.

[45] BS EN 13057:2002, Determination of Resistance of Capillary Absorption, British Standards Institution, 2002.

[46] S. Fennis, J.C. Walraven, J.A. Den Uijl, Compaction-interaction packing model: regarding the effect of fillers in concrete mixture design, Mater. Struct. 46 (2013) 463-478.

[47] ASTM C1437-15, Standard Test Method for Flow of Hydraulic Cement Mortar, ASTM International, 2015.

[48] H. Neuber, Der zugbeanspruchte Flachstab mit optimalem Querschnittsübergang, Forschung Im Ingenieurwesen A. 35 (1969) 29-30, https://doi.org/10.1007/ BF02559032.

[49] E. Denarié, M. Maître, D. Conciatori, E. Brühwiler, Air permeability measurements for the assessment of the in situ permeability of cover concrete, in: International Conference on Concrete Repair, Rehabilitation and Retrofitting, Cape Town, South Africa, 2005, pp. 475-481.

[50] A. Helbling, E. Brühwiler, Eine neue Halterung für Zugversuche mit BetonProbekörper, Material Und Technik. 15 (1987) 103-107.

[51] E. Denarie, E. Brühwiler, Structural rehabilitations with ultra-high performance fibre reinforced concretes (UHPFRC)/Strukturelle Instandsetzung von Betonbrücken mit Ultra-hochleistungsfähigem Faserfeinkornbeton (UHFB), Restoration of Buildings and Monuments. 12 (2006) 93-108.

[52] A. Kamen, E. Denarie, E. Brühwiler, Thermal effects on physico-mechanical properties of ultra-high-performance fiber-reinforced concrete, ACI Mater. J. 104 (2007) 415.

[53] A. Loukili, A. Khelidj, P. Richard, Hydration kinetics, change of relative humidity, and autogenous shrinkage of ultra-high-strength concrete, Cem. Concr. Res. 29 (1999) 577-584.

[54] V. Waller, Relations entre composition des bétons, exothermie en cours de prise et résistance en compression, in, Doctoral Thesis, Thèse de doctorat de L'école Nationale des Ponts et Chaussées, LCPC, 1999.

[55] O.M. Jensen, P.F. Hansen, Water-entrained cement-based materials: I. Principles and theoretical background, Cement and Concrete Research. 31 (2001) 647-654.

[56] C.J. Adendorff, W.P. Boshoff, G. Van Zijl, Characterisation of crack distribution of strain-hardening cement composites (SHCC) under imposed strain, in: Advances in Cement-based Materials, 2010.

[57] P. Zhang, W. Ma, F. Wittmann, W. Wang, T. Zhao, Influence of steel fiber content on fracture energy of HPFRCC, in: High Performance Fiber Reinforced Cement Composites (HPFRCC7), Germany, Stuttgart, 2015, pp. 119-125.

[58] NF P18-710: National Addition to Eurocode 2-Design of Concrete Structures: Specific Rules for Ultra-high Performance Fiber-reinforced Concrete (UHPFRC), AFNOR. (2016).

[59] Fib Model Code for Concrete Structures 2010, Berlin, Germany, 2013.

[60] A. Rafiee, Computer Modeling and Investigation on the Steel Corrosion in Cracked Ultra High Performance Concrete, Doctoral Thesis. 21 (2012). 